\title{
Review on Fundus Image Acquisition Techniques with Data base Reference to Retinal Abnormalities in Diabetic Retinopathy
}

\author{
Kade Mahesh $\mathrm{K}$ \\ BMIT, Solapur
}

\author{
Kashid Nilesh S \\ NBNSCOE, Solapur
}

\begin{abstract}
The purpose of this paper is to Provide the information regarding Diabetic retinopathy, its imaging methods and data base in systematic manner. In this paper we Introduce the terms related to Diabetic Retinopathy along with the characteristic and features of appearance in the images. In this paper we also discuss the various image acquisition techniques of retina from fundus photography to 3D OCT Imaging. lastly we also provide the list of the current data base available with the ground truth . In Diabetic retinopathy the blood vessel becomes weak and due to this vessel leaks blood and fluid of lipoproteins, this creates abnormalaties in retina. Abnormal retinal images form four different classes namely non-proliferative diabetic retinopathy (NPDR), Central retinal vein occlusion (CRVO), Choroidal neovascularisation membrane (CNVM) and central serous retinopathy (CSR) .There may exist different kinds of abnormal lesions caused by diabetic retinopathy in a diabetic's eye. The lesion types are Microaneurysm, Hard Exudate, Soft Exudate, Hemorrhage, and Neovascularization.
\end{abstract}

Keyword: DiabeticRetinopathy,Ground truth,Fundus.

\section{Introduction}

Fundus (Latin for "bottom") is an anatomical term referring to the portion of an organ opposite from its opening. The fundus of the eye is the interior surface of the eye, opposite the lens, and includes the retina, optic disc, macula and fovea, and posterior pole. Fundus (eye) human fundus (from a lightly pigmented blond person) is red The eye's fundus is the only part of the human body where the microcirculation can be observed directly. The fundus is the back of the eye and it can be seen through

the pupil. The retina is the tissue where the image is projected. The retina contains light sensitive cells called cones and rods, which are responsible for daytime and night vision, respectively. The optic nerve transfers information of the projected image from the retina to the brain. The head of the optic nerve, called optic disk or papilla, does not contain receptors itself, and is thus the blind spot of the eye. The macula is an oval spot near the center of the retina with a diameter of about 1.5 millimeters. The fovea is near the center of the macula and it contains packed cone cells. Due to high amount of light sensitive cells, the fovea is responsible for the most accurate vision.

\subsection{Abnormalaties}

Diabetic retinopathy is one of the complications caused by diabetes. As indicated by the name, diabetic retinopathy appears in the retina, which is the tissue responsible for vision in the eye. Since diabetic retinopathy causes changes in the eye, the disease may affect the vision. In Diabetic retinopathy the blood vessel becomes weak and due to this vessel leaks blood and fluid of lipoproteins this creates abnormalaties in retina.There may exist different kinds of abnormal lesions caused by diabetic retinopathy in a diabetic's eye. The lesion types are briefly described: microaneurysm, hard exudate, soft exudate, hemorrhage, and neovascularization. The features of different abnormal lesion types are shown in Table I. (next page)

Microaneurysms are the earliest clinically detectable lesions [3], [13], [14], and thus it is important to have a method for detecting microaneurysms so that incipient retinopathy may be noticed in its early stages. Microaneurysms are local distensions of retina capillary[14]. These outpouchings of capillary walls can be seen as tiny, round, red dots [3]. See fig (b) .The image is magnified,but it is still difficult to distinguish the microaneurysm due to its small size. When microaneurysms are coated with blood, they may be indistinguishable from dot hemorrhages [3].Thus, the term "red small dot" is used to cover both microaneurysms and small dot hemorrhages. Microaneurysms are not necessarily permanent changes, but they may first appear and then disappear during some period of time [13], [14].Intra-retinal hemorrhages appear when capillaries or microaneurysms rupture [17] and some blood leaks out of the vessels. Hemorrhages can be seen as red, dot-blot or flameshaped regions [3]. A fundus with multiple hemorrhages is shown in Figure (c).Hard exudates are accumulated lipid formations leaked from weakened vessels [13], [17].Hard exudate lesions are waxy and yellow with relatively clear edges [3]. Hard exudates often appear in clusters or rings [3]. Figure (d) represents a fundus where multiple hard exudates appear as bright lesions. Soft exudates, also called cotton wool spots or micro-infarctions, appear when terminal retinal arterioles are obstructed [17], [13]. Soft exudates are small, whitish lesions with blurry edges [3]. Figure (e) shows a magnified fundus image where a soft exudates lesion is marked with an arrow. As seen in the figure, soft exudates are not usually as visible as hard exudates. Extensive lack of oxygen caused by obstructions may lead to development of new blood vessels that are weak and can therefore easily tear [14], [18], [13], [17]. The disease where new blood vessels appear is called neovascularization. Neovascularization is the most serious abnormality type in diabetic retinopathy since profuse bleeding may produce loss of vision [18]. Figure(f) shows a fundus with neovascularization. New small vessels have appeared on the optic disk that is marked with an arrow in the image. The other arrow shows a hemorrhage lesion where blood has leaked from a new blood vessel. 
.Table I

\begin{tabular}{|c|c|c|c|c|c|}
\hline Lesion type & Size & Color & Shape & Other & Description \\
\hline Microaneurysm & very small & Dark red & Round-shaped & & $\begin{array}{l}\text { Distensions (swell due to } \\
\text { pressure from inside ) in the } \\
\text { capillary }\end{array}$ \\
\hline Hemorrhage & $\begin{array}{l}\text { from small to } \\
\text { large }\end{array}$ & Dark red dot & Flame-shaped & & $\begin{array}{l}\text { Caused by ruptured or } \\
\text { permeable capillaries }\end{array}$ \\
\hline Hard exudate & $\begin{array}{l}\text { from small to } \\
\text { medium }\end{array}$ & $\begin{array}{l}\text { Yellow } \\
\text { glistening } \\
\text { appearance }\end{array}$ & Not regular & clear edges & $\begin{array}{l}\text { Caused by leaking lipid } \\
\text { formations }\end{array}$ \\
\hline Soft exudate & $\begin{array}{l}\text { from small to } \\
\text { medium }\end{array}$ & Whitish & $\begin{array}{l}\text { Usually oval } \\
\text { shaped }\end{array}$ & $\begin{array}{l}\text { Blurry } \\
\text { edges }\end{array}$ & $\begin{array}{l}\text { (microinfarcts), a very small } \\
\text { infarct due to obstruction of } \\
\text { circulation in capillaries, } \\
\text { arterioles, or small arteries }\end{array}$ \\
\hline Neovascularization & varies & Red & varies & $\begin{array}{l}\text { new blood } \\
\text { vessels }\end{array}$ & New fragile blood vessels \\
\hline
\end{tabular}
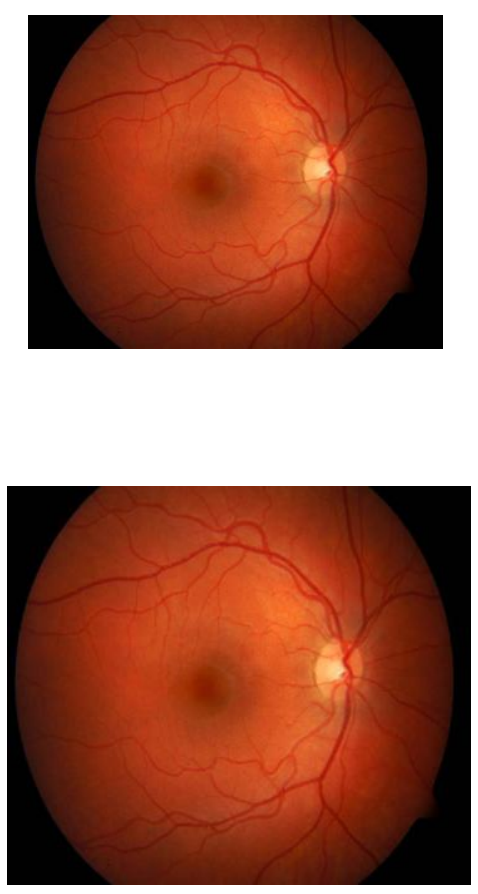

Fig (a)

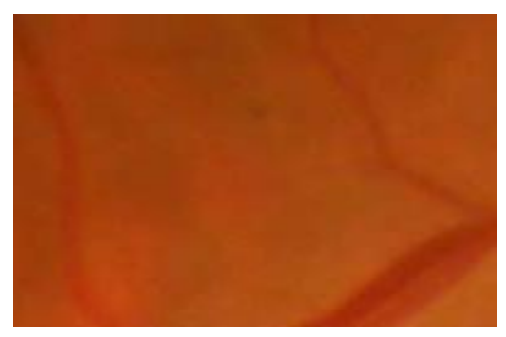

$\operatorname{Fig}(\mathbf{b})$

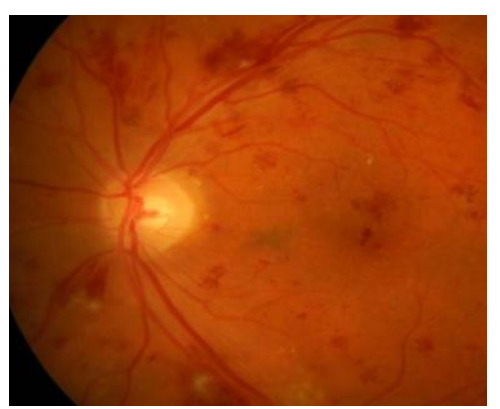

$\operatorname{Fig}(\mathbf{c})$ 


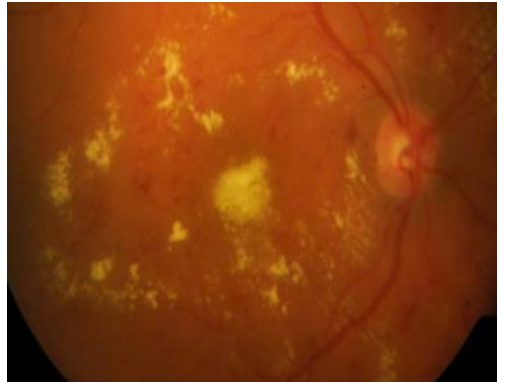

Fig( d)

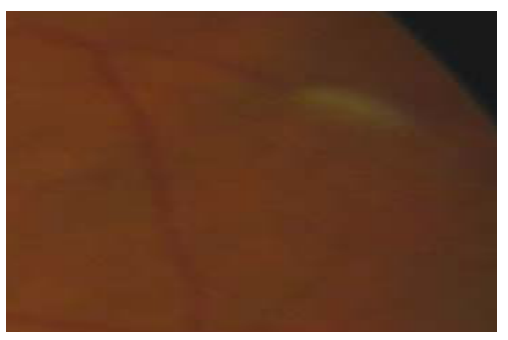

Fig(e)

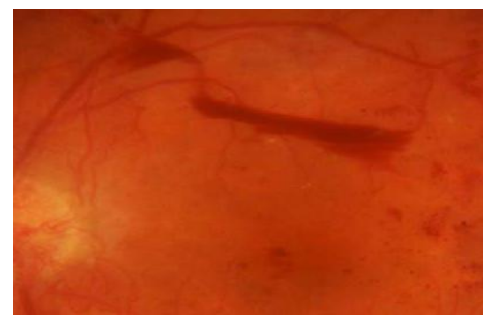

$\operatorname{Fig}(\mathbf{f})$

Abnormalities belonging to diabetic retinopathy: (b) Microaneurysm (small red lesion); (c) Hemorrhages (dark red lesions); (d) Hard exudates (yellow lesions); (e)Soft exudates (yellow/whitish lesion); (f) Neovascularization (new blood vessels).

From the Abnormalaties of retina due to diabetic .Seriousness of diabetic retinopathy is given by levels and The grading of diabetic retinopathy is classified as shown in Table II

Table II : Grading of Diabetic Retinopathy

\begin{tabular}{|c|c|c|c|}
\hline $\begin{array}{l}\mathrm{S} \\
\mathrm{r}\end{array}$ & level & Name & Characteristic \\
\hline 1 & 0 & Normal & $(\mu \mathrm{A}=0)$ AND $(\mathrm{H}=0)$ \\
\hline 2 & 1 & $\begin{array}{l}\text { Background/N } \\
\text { on proliferative }\end{array}$ & $\begin{array}{l}0<\mu \mathrm{A}<=5) \text { AND }(\mathrm{H} \\
=0)\end{array}$ \\
\hline 3 & 2 & $\begin{array}{l}\text { Pre- } \\
\text { proliferative }\end{array}$ & $\begin{array}{l}((5<\mu \mathrm{A}<15) \text { OR }(0 \\
<\mathrm{H}<5)) \text { AND }(\mathrm{NV}= \\
0)\end{array}$ \\
\hline 4 & 3 & Proliferative & $\begin{array}{l}(\mu \mathrm{A}>=15) \text { OR }(\mathrm{H} \\
>=5) \text { OR }(\mathrm{NV}=1)\end{array}$ \\
\hline 5 & $\begin{array}{l}\text { Maculopa- } \\
\text { thy level } 0\end{array}$ & $\begin{array}{l}\text { Maculopath-y } \\
\text { level } 0\end{array}$ & $\begin{array}{l}\text { No visible hard } \\
\text { exudates }\end{array}$ \\
\hline 6 & Maculopathy & Maculopathy & Shortest distance \\
\hline
\end{tabular}

\begin{tabular}{|l|l|l|l|}
\hline & level 1 & level 1 & $\begin{array}{l}\text { between macula and } \\
\text { hard exudates one } \\
\text { papilla diameter }\end{array}$ \\
\hline 7 & $\begin{array}{l}\text { Maculopathy } \\
\text { level 2 }\end{array}$ & $\begin{array}{l}\text { Maculopathy } \\
\text { level 2 }\end{array}$ & $\begin{array}{l}\text { Shortest distance } \\
\text { between macula and } \\
\text { hard exudates <= one } \\
\text { papilla diameter }\end{array}$ \\
\hline 8 & $\begin{array}{l}\text { Unclassifiabl } \\
\text { e }\end{array}$ & Unclassifiable & $\begin{array}{l}\text { Ungradable/unobtaina } \\
\text { ble }\end{array}$ \\
\hline
\end{tabular}

$\mu \mathrm{A}$ : number of microaneurysms ,H: number of hemorrhages, $\mathrm{NV}=$ : Neovascularization

\section{$2 \quad$ History of imaging}

The first attempt to image the retina in a cat was completed by the French physician Jean Mery, who showed that if a live cat is immersed in water, its retinal vessels are visible from the outside. The impracticality of such an approach for humans lead to the invention of the principles of the ophthalmoscope in 1823 by Czech scientist Jan Evangelista Purkyn`e (frequently spelled Purkinje) and its reinvention in 1845 by Charles Babbage [48], [49]. Babbage also originated the concept of a programmable computer and thus the link between computation [49a] .Finally, the ophthalmoscope was reinvented again and reported by von Helmholtz in 1851 [50]. Thus, inspection and evaluation of the retina became routine for ophthalmologists, and the first images of the retina were published by the Dutch ophthalmologist van Trigt in 1853 . Earlier sketches by Purkyn $` e$ provided drawings of his own retinal vasculature The first useful photographic images of the retina, showing blood vessels, were obtained in 1891 by the German ophthalmologist Gerloff [53]. In 1910, Gullstrand developed the fundus camera, a concept still used to image the retina today[53], he later received the Nobel Prize for this invention.Because of its safety and cost-effectiveness at documenting retinal abnormalities, fundus imaging has remained the primary method of retinal imaging. The next important development was the invention of fluorescein angiographic imaging, where a fundus camera with additional narrow band filters is used to image a fluorescent dye injected into the bloodstream that binds to leukocytes [54]. It remains widely used because it allows an understanding of the functional state of the retinal circulation. Concerns about safety and cost-effectiveness are leading it to be slowly replaced by tomographic imaging methods for its primary applications, namely image-guided treatment of macular edema and the "wet form" of macular degeneration. A major limitation of fundus photography is that it obtains a 2-D representation of the 3-D semi-transparent retinal tissues projected onto the imaging plane. The initial approach to depict the 3-D shape of the retina was stereo fundus photography, as first described by Allen in 1964 [55], where multi-angle images of the retina are combined by the human observer into a 3-D shape. Subsequently, confocal scanning laser ophthalmoscopy was developed, using the confocal aperture to obtain multiple images of the retina at different confocal depths, yielding estimates of 3-D shape. However, the optics of the eye limit the depth resolution of confocal imaging to approximately $100 \mathrm{~mm}$ which is poor when compared with the typical 300-500 mm thickness of the whole retina [56]. Tomographic imaging of the retina became commonplace with the development of superluminescent diodes, femtosecond lasers and the application of optical coherence tomography (OCT) to retinal imaging [57], which allows truly 3-D optical sectioning of the retina Matsui 
et al. were the first to publish a method for retinal image analysis, primarily focused on vessel segmentation [59].

2.1 Fundus Imaging We define fundus imaging as the process whereby a 2-D representation of the 3-D retinal semitransparent tissues projected onto the imaging plane is obtained using reflected light. Thus, any process which results in a 2-D image, where the image intensities represent the amount of a reflected quantity of light, is fundus imaging. image intensities represent the amount of reflected light of a specific waveband; Since retinopathy lesions are visible in the fundus,the examination can be simply performed by viewing the funduses of diabetic's eyes using the natural way of the light: light is directed through the pupil to the retina and the fundus with its normal and abnormal parts can be observed from the reflected light. CR4-45NM camera Non-Mydriatic Retinal Camera is used. The $35 \mathrm{~mm}$ camera body should be attached to the main unit and loaded with a fresh roll of Kodachrome 64, 24 exposure color slide film The best photographs are obtained when the eye is well dilated, fixation is on the target; and lids and lashes are held wide open.

2.2 Color fundus photography - image intensities represent the amount of reflected R, G, and B wavebands, as determined by the spectral sensitivity of the sensor; . One way to register the light reflecting from the fundus is to use a color fundus camera. Two RGB color fundus images taken by a fundus camera .see fig (g,h) Alternatively, different filters and a gray-level camera can be used to catch wavelengths of interest. A very common method is to use a green filter for getting wavelengths of green color and register the filtered light using a gray-level camera. Fundus photography is performed by a fundus camera, which basically consists of a specialized low power microscope with an attached camera. The optical design of fundus cameras is based on the principle of monocular indirect ophthalmoscopy. A fundus camera provides an upright, magnified view of the fundus. A typical camera views 30 to $50^{\circ}$ of retinal area, with a magnification of $2.5 \mathrm{x}$, and allows some modification of this relationship through zoom or auxiliary lenses from $15^{\circ}$, which provides $5 \mathrm{x}$ magnification, to $140^{\circ}$ with a wide angle lens, which minifies the image by half.
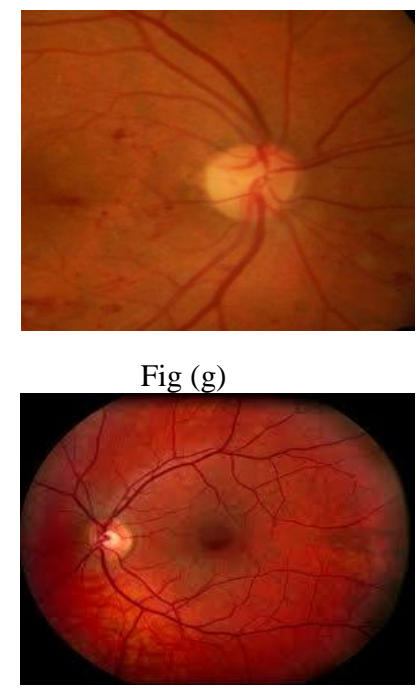

Fig $(h)$
2.3 Stereo fundus photography — image intensities represent the amount of reflected light from two or more different view angles for depth resolution. See fig (i). Stereo photography creates two images of the same subject taken from two positions-that of the photographer's left eye and that of the photographer's right eye. After being processed, the images are then presented to the appropriate eye for viewing and the viewer's brain recreates the three-dimensional view. The goal of this process is to recreate the image as if the viewer were at the site of the photography. In stereo photographs, the optical systems are kept parallel to each other and perpendicular to the plane of the subject. This introduces the least amount of distortion in the film Image , and for the same reason, images should be viewed parallel to the visual plane. The distance between the two optical systems is called the stereo base. Sequential stereo photography can be used to increase the depth-of-field by combining two images that are focused at slightly different planes of focus. Stereo images can be displayed on the monitor or printed on paper (from the computer image file).Zeiss 30-degree cameras can be used. Stereo imaging is recommended, for example, for all photographs of the optic nerve head.

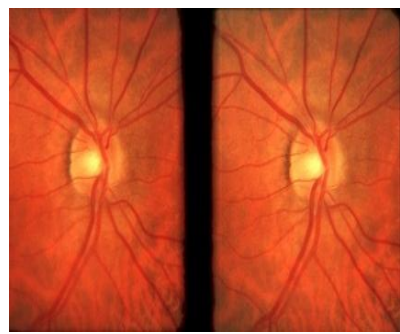

Fig (i)

2.4 Hyperspectral imaging-image intensities represent the amount of reflected light of multiple specific wavelength bands. Hyperspectral images contain a wealth of data . see fig (j) Hyperspectral imaging of the human retina is a relatively new concept that has the potential to determine the metabolic status of the retina.Roper VersArray 512B back illuminated CCD with a Basler A601 CMOS camera.of 495- to $720-\mathrm{nm}$ wavelengths is used to collect image data simultaneously in dozens or hundreds of narrow, adjacent spectral bands. hyperspectral retinal imaging system consisting of a modified commercial fundus camera, a liquid crystal tuneable filter and a low-noise CCD detector was used to capture sequential hyperspectral images of the human retina. A hyperspectral data cube with a spectral bandwidth of $500 \mathrm{~nm}$ to $700 \mathrm{~nm}$ and a spectral resolution of $10 \mathrm{~nm}$ atwavelength steps of $2 \mathrm{~nm}$ can be obtained. The hyperspectral technique allows wavelength-specific visualization of retinal lesions that may be subvisible using a white light source camera. This hyperspectral technique may facilitate localization of retinal and disc pathology and consequently facilitate the diagnosis and management of retinal disease. hyperspectral deals with imaging narrow spectral bands over a continuous spectral range, and produce the spectra of all pixels in the scene . Hyperspectral images are produced by instruments called imaging spectrometers Spectroscopy is the study of light that is emitted by or reflected from materials and its variation in energy with wavelength. Reflectance varies with wavelength for most materials because energy at certain wavelengths is scattered or absorbed to different degrees. Hyperspectral 
imaging is capable of detecting oximetric changes in the retina and monitoring its response to treatment.

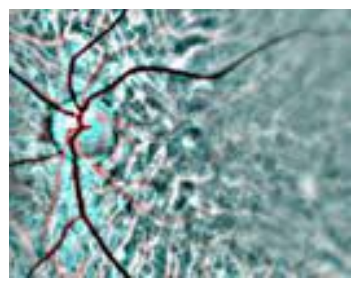

Fig (j)

\subsection{Scanning laser ophthalmoscopy (SLO)-}

image intensities represent the amount of reflected single wavelength laser light obtained in a time sequence. SLO utilizes horizontal and vertical scanning mirrors to scan a specific region of the retina and create raster images viewable on a television monitor. See fig (k) While it is able to image the retina in real time, it has issues with reflections from eye astigmatism and the cornea. Eye movements additionally can confound the data from SLO Unlike conventional photography, which obtains two-dimensional imaging, scanning laser techniques utilize confocal imaging methods to obtain highresolution images both perpendicular (x-axis, y-axis) to optic axis and along the optic axis (z-axis) .The Heidelberg Retina Tomograph II (HRT II) represents the latest iteration in the application of confocal scanning laser ophthalmoscopy to the examination of the optic disc. The HRT II is a scanning laser ophthalmoscope specifically designed to acquire threedimensional images of the optic nerve head and posterior pole. The depth of the focal plane is automatically adjusted by shifting the confocal aperture to acquire multiple optical sections through the tissue of interest in order to create a layered three-dimensional image . Rapid scanning of 670-nm diode laser is done The intensity of the scanning diode laser is 100 times lower than the luminance of a digital fundus flash camera, making the imaging process much more comfortable to the patient than with conventional fundus photography. As a method used to image the retina with a high degree of spatial sensitivity, is helpful in the diagnosis of glaucoma, macular degeneration, and other retinal disorders. lateral resolution from AOSLO has been the ability to determine the spatial distribution of cone cells around the fovea. The imaging of Retinal Pigment Epithelium (RPE) optic nerve head and posterior pole. It has greater translational resolution than OCT. see below fig(k)

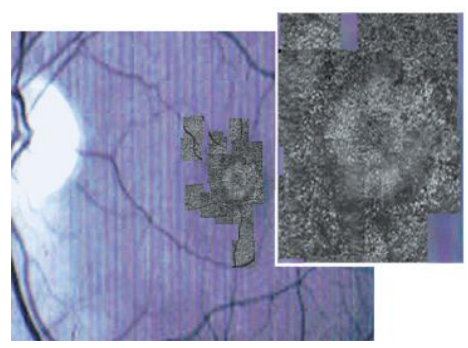

Fig (k)

2.6 Adaptive optics $S L O$ _image intensities represent the amount of reflected laser light optically corrected by modeling the aberrations in its wavefront .Adaptive optics scanning laser ophthalmoscope that includes an integrated retinal tracker and an auxiliary wide-field imager called tracking adaptive optics scanning laser ophthalmoscope,
TAOSLO The estimation of nerve fiber layer thickness in normal and glaucomatous eyes, tracking provided little benefit due to the small spatial gradient of that layer.

\subsection{Fluorescein angiography and indocyanine} angiography — image intensities represent the amounts of emitted photons from the fluorescein or indocyanine green fluorophorensce that was injected into the subject's circulation . In this method, a fluorescent liquid injection is given to the patient before the angiogram is taken In fluorescein angiograms, the parts of the retina where blood mostly flows are visible as bright whereas other parts of the retina appear dark. Thus, blood vessels and microaneurysms can be easily seen in fluorescein angiograms since they appear brighter than other parts of the retina. See fig $(1, \mathrm{~m}$.) Hemorrhage lesions contain blood that does not flow, and thus they are visible as dark regions in fluorescein angiograms. However, fluorescein angiograms have a disadvantage that makes them inconvenient: the need of an injection. fluorescein angiography. It can detect diabetic retinopathy (neovascularization), vein occlusions, retinal artery occlusions, edema of the optic disc, and tumors

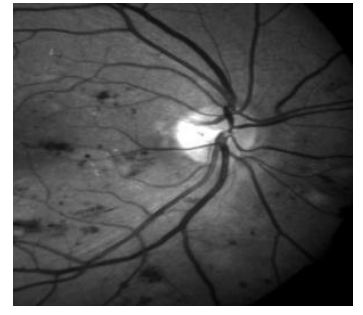

Fig(l)

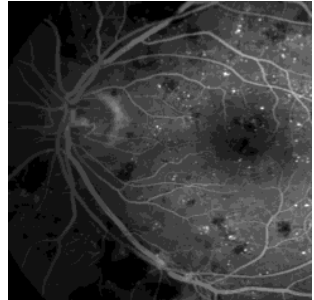

Fig $(m)$

\subsection{Optical Coherence Tomography Imaging}

The principle of Optical Coherence Tomography (OCT) is the estimation of the depth at which a specific backscatter originated by measuring its time of flight. Backscatters are typically caused by differences in refractive index in transitions from one tissue to another. The backscatter from deeper tissues can be differentiated from backscatter originating at more superficial tissues because it takes longer for the light to arrive at the sensor. As the total retinal thickness is between 300-500 $\mathrm{mm}$, the differences differences in time of flight are very small and can only be measured through interferometry [57]. There is a great similarity between ultra-sonography and optical coherence tomography, in that they both image by reflecting an impulse of energy onto the subject matter being studied and analyzing the energy reflected back. The difference is that sonography uses sound waves, which can penetrate opaque matter, and OCT uses light waves, which only penetrate translucent matter. Because light waves have a much shorter wave length than sound waves, there is much greater/better resolution in image presentation. OCT is currently most often used to examine the macula in ARMD (age-related macular degeneration). In this condition abnormalities in the retinal tissue can be identified and measured. These abnormalities include breaks in the outer retina tissues, accumulation of metabolic by-products, fluid under or in the retina, scar tissue under the retina or on the surface of the retina, and traction on the macula and/or surrounding retina. Because of its high resolution the individuals layers of the retina can be identified, aiding in the diagnosis of the macular and retinal condition. 
OCT employs low-coherent light interferometry, also called white light interferometry-though the wavelengths used for OCT are usually slightly longer than visible light. Lowcoherent light autocorrelates only for a short amount of time, or equivalently,for only a small number of wavelengths, while autocorrelation function values are essentially zero beyond that. Low-coherent illumination can be thought of as a train of highly autocorrelated overlapping "bursts" of light — each burst labeled by its unique autocorrelogram.Has greater axial resolution and less translational resolution OCT is used to differentiate tissues within the eye and create a cross section disorder of macula region macula oedema, epiretinal membrane,macular hole ,pucker, optic nerve damage, nerve swelling, and the degree of nerve fiber loss and location. It can also reveal vitreous traction on the optic nerve. It is used to evaluate the optic nerve, the OCT quantitates the amount of optic nerve damage, nerve swelling, and the degree of nerve fiber loss and location. It can also reveal vitreous traction on the optic nerve.optical coherence tomographer is invaluable in evaluating the progression of a disease, as well as, showing if the condition is responding to treatment.

OCT are divided into 1) Time-domain OCT, or time-of-flight OCT, 2) Swept-source or time encoded frequency domain OCT, 3) Spectral-domain OCT , 4 Longer Wavelength OCT Imaging 5 )Three-Dimensional OCT Imaging

\subsubsection{Time-domain OCT, or time-of-flight OCT}

Time domain Stratus OCT (Stratus OCT, Version 4.0.1, Carl Zeiss Meditec, Dublin, CA, USA) uses a superluminescent diode source (wavelength $810 \mathrm{~nm}$, bandwidth $20 \mathrm{~nm}$ ) and generates retinal thickness map from six consecutive radial Bscans. where depth informations of the retina are obtained after a longitudinal translation in time of a reference arm. TD-OCT produces two-dimensional images of the sample internal structure. In TD-OCT, tissue-reflectance information in depth (an A-scan represents a reflectivity profile in depth) is gradually built up over time by moving a mirror in the reference arm of the interferometer. OCT B-scans (a B-scan represents a cross-section image, a lateral $\mathrm{x}$ depth map) are generated by collecting many A-scans. An interferometer measures sequentially the echo delay time of light that is reflected by the retinal microstructures It samples one point at the time 6 radial scans, image resolution is $20 \mu$ wide and 6 $\mathrm{mm}$ long.The area between the 6 scans is not imaged . rate of acquisition is 400 scans/second . Two-dimensional images of nternal structure is possible

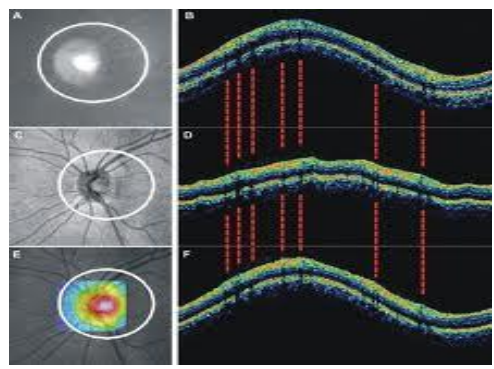

Fig (n)

\subsubsection{Swept-source or time encoded frequency \\ domain OCT is a differential 1300nm SS-OCT system} based on a swept laser with an $87 \mathrm{~nm}$ tuning range The first, Fourier-domain OCT (FD-OCT) uses a broadband light source and achieves spectral discrimination with a dispersive spectrometer in the detector arm The second method, sweptsource OCT (SS-OCT) [2,6-9], time-encodes wavenumber by rapidly tuning a narrowband .The superior sensitivity (defined as the signal-to-noise ratio for a perfect sample reflector )of swept source (SS) and Fourier domain (FD) optical coherence tomography (OCT) techniques over the conventional time domain (TD) approach.

\subsubsection{Spectral-domain OCT SD-SLO/OCT produced} fewer artefacts than Stratus TD-OCT. This could be attributed to the greater resolution and acquisition speed of SD-SLO/OC speeds 50 times faster than TD-OCT, and providing a greater number of images per unit area. This increase in resolution and scanning speed allows high-density raster scanning of retinal tissue while minimizing eye motion artefacts. several SD-OCT devices introduced to clinical practice use different algorithms to calculate retinal thickness. In spectral domain scanning laser ophthalmoscope/OCT (SLO/OCT, Ophthalmic Technologies Inc., Toronto, Canada) a super luminescent diode produces a light with a wavelength of $840 \mathrm{~nm}$ (bandwidth $150 \mathrm{~nm}$ ). A spectrometer measures the interference spectrum between back reflected light from the tissue and light from a stationary reference arm. The Fourier transform of this interference spectrum allows to measure the magnitude and echo time delay of the light signal from the tissue. This provides simultaneous measurements of light echoes

from different axial depths, without movement of the reference arm . Retinal thickness value measured is higher than Time domain light with a wavelength of $840 \mathrm{~nm}$ (bandwidth 150 $\mathrm{nm})$. SD-OCT can be implemented in two formats, Fourier domain (FD-OCT) and swept source (SS-OCT). SD-OCT units acquire entire A-scans in reflected light at a given point in tissue. Information on depth is transformed from the frequency domain to the time domain, without using a moving reference mirror to obtain complete A-scans. The absence of moving parts allows the image to be acquired rapidly - about 60 times faster than with TDOCT. The SD-OCT units allow the improvement of the detection and monitoring of retinal diseases, because these ones have ultra high-speed scan rate, superior axial and lateral resolution, cross-sectional (2D) scan, $3 \mathrm{D}$ raster scanning and a higher imaging sensitivity than the traditional TD-OCT units. The SD-OCT software permits many operations with 3D data compared with traditional TDOCT The great number of scans done per time unit also allows SD-OCT systems to generate 3D reconstructions, which can be further manipulated. Visualization of this data in 3D demonstrates subtle pathology not evident with conventional 2D images. The Fourier transformation allows the simultaneous measurement of the light reflection with a spectrometer . It samples all the points simultaneously 60 times faster than TD-OCT. 65.000 scans in a 6- $\mathrm{mm}$ area, without excluding areas . Rate of acquisition $20.000-40.000$ scans/second. 3D reconstruction is possible. Image resolution and quality is $1 \mu$, see Fig(o) 


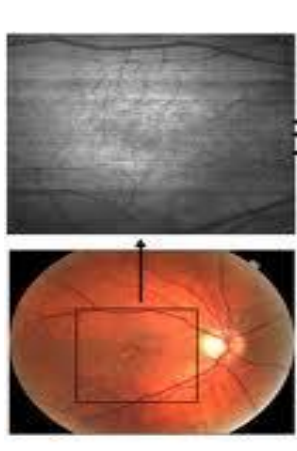

Fig (o)

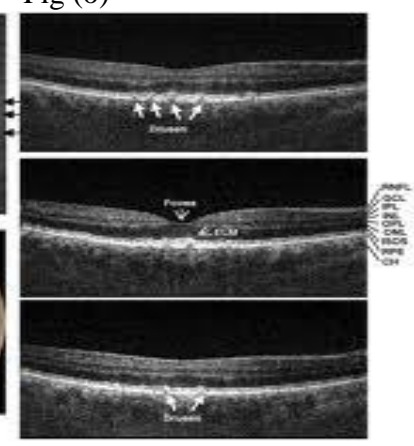

\subsubsection{Three-Dimensional OCT Imaging}

With the use of two SD-OCT devices, we can obtained 3D SD-OCT data within $6 \times 6 \times 1.4-\mathrm{mm}$ and $6 \times 6 \times 2-\mathrm{mm}$ volumes, respectively, centered on the fovea in healthy eyes and in eyes with retinal pathology. C-mode images were generated by sampling a variable thickness plane semiautomatically modeled to fit the contour of the SoI. To visualize structures of interest (SoIs) along their contour within three-dimensional, spectral domain optical coherence tomography (3D SD-OCT) data is required for eg striation of retinal nerve fiber (RNF), retinal capillary network (RCN), choroidal capillary network $(\mathrm{CCN})$, and major choroidal vasculature $(\mathrm{CV})$. Various SoI structure of interest were visualized using 3D OCT. see fig (p) below

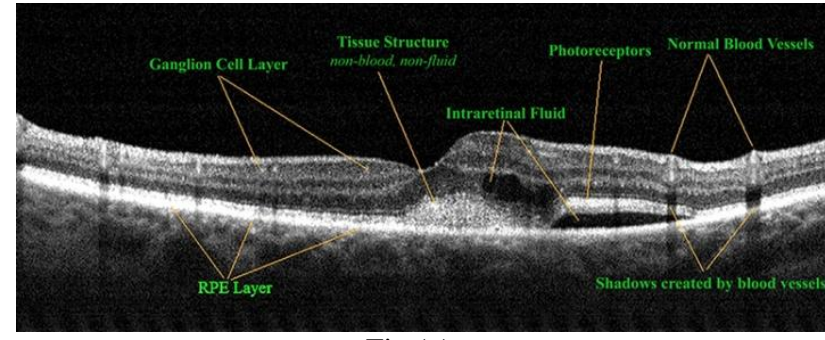

Fig (p)

2.8.5 Longer Wavelength OCT Imaging At 1.7 micrometers used for enhanced imaging depth. It offer an advantage over shorter wavelengths by increasing the penetration depths as well as enhancing image contrast at deeper penetration depths where otherwise multiple scattered photons dominate over ballistic photons. Results achieved with 3-D OCT at $1050 \mathrm{~nm}$ reveal, for the first time, decisive improvements in image quality for patients with retinal pathologies and clinically significant cataract.

Table III show s the summary of imaging methods and its specific use in abnormalaties of Diabetic retinopathy.

Table III

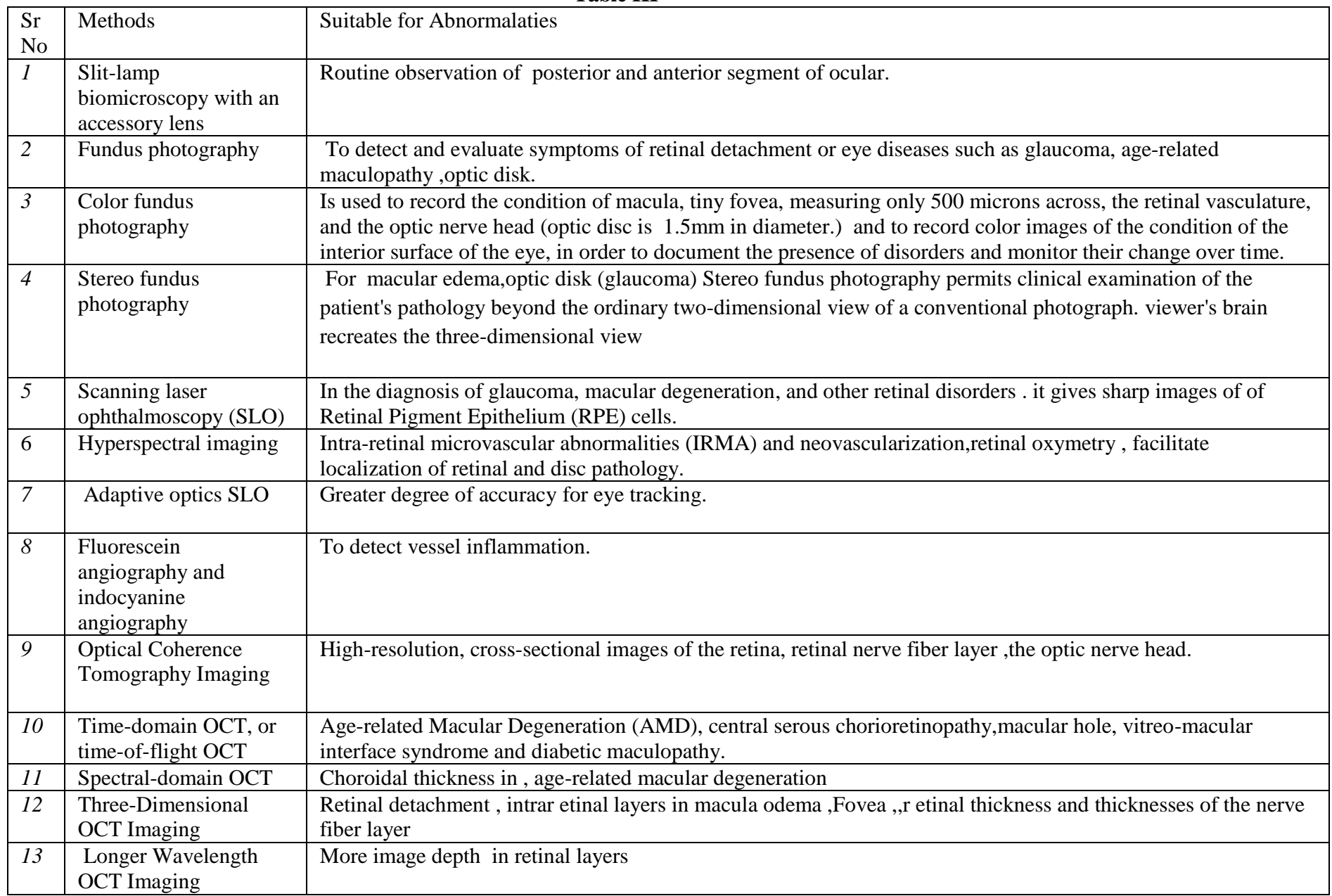




\section{Database for retinal images}

Retinal fundus image is an important modality to document the health of the retina and is widely used to diagnose ocular diseases such as glaucoma, diabetic retinopathy and agerelated macular degeneration. However, the enormous amount of retinal data obtained nowadays mostly stored locally and the valuable embedded clinical knowledge is not efficiently exploited. In this paper we present an list of available data base that I know and is given in TableIV below

Table IV

\begin{tabular}{|c|c|c|c|c|}
\hline $\mathrm{Sr}$ & Database & $\begin{array}{l}\text { Images and pixel size } \\
\text { camera used ,file format }\end{array}$ & Ground truth & Contact /university \\
\hline 1 & $\begin{array}{c}\text { STARE } \\
\begin{array}{l}\text { Structured analysis of } \\
\text { retina }\end{array}\end{array}$ & $\begin{array}{l}31 \text { healthy } 50 \text { disease } \\
605 * 500\end{array}$ & Vessel & Ces.clemson.edu/ahoover/stare \\
\hline 2 & $\begin{array}{c}\text { DRIVE } \\
\text { Digital retinal analysis } \\
\text { for vessel extraction }\end{array}$ & $\begin{array}{l}40 \\
565 * 590,768 * 584 \\
\text { Canon CR5 nonmydriatic } \\
3 \mathrm{CCd}, 45 \mathrm{FOV}\end{array}$ & Vessel & Isi.uu.ne/research/database/drive \\
\hline 3 & DIARETDB1 & 89 & $\begin{array}{l}\text { Microanerusym, } \\
\text { Hemorrages, } \\
\text { hard exudates ,soft } \\
\text { exudates }\end{array}$ & It.lut.fi/project/ \\
\hline 4 & DIARETDBO & $\begin{array}{l}130 \\
20 \text { normal } \\
110 \text { pathological } \\
1550 * 1152 \text { png Format }\end{array}$ & $\begin{array}{l}\text { Microanerusym, } \\
\text { Hemorrages, } \\
\text { hard exudates ,soft } \\
\text { exudates }\end{array}$ & It.lut.fi/project \\
\hline 5 & $\begin{array}{c}\text { MESSIDOR } \\
\text { Method to evaluate } \\
\text { segmentation and } \\
\text { indexing techniques in } \\
\text { field of retinal } \\
\text { opthamology }\end{array}$ & $\begin{array}{l}1200 \\
1490 * 960 \\
1440 * 960, \quad 2240 * 1488 \quad \text { or } \\
2304 * 1536 \text { pixels. } \\
\text { Tiff format } \\
\text { Topcon TRCNW6,45 FOV }\end{array}$ & Retinopathy grading & Messidor.crihan.fr \\
\hline 6 & $\begin{array}{l}\text { Retinopathy online } \\
\text { Challenge }\end{array}$ & 100 & MA, hemorrhages & Roc.healthcare .uiowa.edu IOWA \\
\hline 7 & HOORN & $\begin{array}{l}191 \text { images } \\
51 \text { are pathologies and } 140 \\
\text { healthy } \\
768 * 584\end{array}$ & Optic disk & $\begin{array}{l}\text { Netherland image } \\
\text { UTRECHT }\end{array}$ \\
\hline 8 & $\begin{array}{c}\text { CMIF } \\
\text { Collection of } \\
\text { multispectral iage } \\
\text { fundus }\end{array}$ & $\begin{array}{l}117 \\
50 \text { training } \\
67 \text { test }\end{array}$ & lesion & $\begin{array}{l}\text { Birmingham university } \\
\text { E.Claridge@cs.bham.ac.uk }\end{array}$ \\
\hline 9 & $\begin{array}{c}\text { REVIEWdb } \\
\text { Retinal veseel image } \\
\text { set for estimation of } \\
\text { width } \\
\end{array}$ & 16 & Vessel & $\begin{array}{l}\text { University of Lincoln } \\
\text { Reviewdb.lincoln.ac.uk }\end{array}$ \\
\hline 10 & $\begin{array}{c}\text { JRD } \\
\text { Junction resolution } \\
\text { data set }\end{array}$ & 99 & Vessel & University of lincoln \\
\hline 11 & $\begin{array}{c}\text { MMRBF } \\
\text { Manual measurement } \\
\text { of retinal bifurcation } \\
\text { feature } \\
\end{array}$ & & Vessel & University of lincoln \\
\hline 12 & $\begin{array}{c}\text { ONHSEG } \\
\text { Optic nerve head } \\
\text { segmentation data set }\end{array}$ & & Optic disk & University of lincoln \\
\hline 13 & $\begin{array}{c}\text { LEDGE } \\
\text { Lesion edge } \\
\text { segmentation }\end{array}$ & & Lesion & University of lincoln \\
\hline
\end{tabular}




\begin{tabular}{|c|c|c|c|c|}
\hline 14 & VARPA & 233 & & $\begin{array}{l}\text { Varpa.es } \\
\text { mortega@udc.es }\end{array}$ \\
\hline 15 & VICAVR & 58 & $\begin{array}{l}\text { For calculation of } \\
\text { arterior vein ratio }\end{array}$ & $\begin{array}{l}\text { Compyo hospital } \\
\text { University of santago }\end{array}$ \\
\hline 16 & $\begin{array}{c}\text { CRIAS } \\
\text { (color retinal image } \\
\text { analysis set) }\end{array}$ & $\begin{array}{l}288 \\
100 \text { training } \\
\text { And } 188 \text { test images }\end{array}$ & MicroAneruysm & L V Prasad eye center Hyderabad \\
\hline 17 & ORIGA & 650 retinal images & Optic disk & Singapore eye research institute \\
\hline 18 & DIARETSPECDB1 & $\begin{array}{l}66 \text { spectral database } \\
1024 \times 1024 \times 30 \text { spectral image }\end{array}$ & $\begin{array}{l}\text { microaneurysms or red } \\
\text { small dots, hard } \\
\text { exudates }\end{array}$ & $\begin{array}{l}\text { Fotonics Color Research Center, university } \\
\text { of Eastern Finland and Kuopio University } \\
\text { Hospital }\end{array}$ \\
\hline
\end{tabular}

The table provides exhaustive information on the available data base along with ground truth,and available website with mail id from where the Data can be downloaded .

\section{Conclusion}

In this paper we have seen the meanings of various lesion in diabetic retinopathy and provided the information of what appearance it takes in images, this appearance is like the characteristic of various abnormalities and is useful in understanding which type of algorithm can be developed to target the lesion .we have also discussed the grading of diabetic retinopathy to understand the seriousness of retinal abnormalaties.The images are to be captured of fundus and there are different methods to capture it and all the methods are briefly discussed along with the sample images of all types to get clear picture how the images look like and helps in designing algorithms. This paper also provides the very comprehensive list of database along with the ground truth and this definitely help the research scholar immensely, as no such comprehensive data base is available made in so far .

\section{References}

[1] Tekes, national technology agency of Finland. Website (referenced 20th February2005). ttp://www.tekes.fi/eng/.

[2] Diabetesliitto: Perustietoa diabeteksestä. Website (referenced 3th February 2005).http://www.diabetes.fi/diabtiet/perus/perus2.htm(I n Finnish)

[3] Jack J. Kanski. Clinical Ophthalmology: A Systematic Approach. Butterworth-Heinemann, 2003. ISBN 0-75065542-9.

[4] Effective Health Care - Complications of diabetes: Renal disease and promotion of self-management. Volume 6, number 1. Royal Society of Medicine Press, 2000.ISSN 0965-0288.

[5] Diabetesliitto: Tyypin 1 diabetes. Website (referenced 3th February

2005) http://www.diabetes.fi/diabtiet/perus/tyyppi1.htm(In Finnish).

[6] Diabetesliitto: Tyypin 2 diabetes. Website (referenced 3th February 2005). http://www.diabetes.fi/diabtiet/perus/tyyppi2.htm(In Finnish).

[7] Diabetesliitto: Diabetes Suomessa. Website (referenced 3th February 2005). http://www.diabetes.fi/diabtiet/tiedote/02/tutkijat.htm (In Finnish).

[8] Helsingin ja uudenmaan sairaanhoitopiiri: Yleistä diabetestyypeistä.Website (referenced 3th February 2005).http://www.hus.fi/default.asp?path=1;32;660;546; 621;763;1193;5104 (In Finnish).

[9] Annele Eerola, Sirkku Kivisaari, Riikka Eela, and Mikko Rask. Ikääntyneiden itsenäistä suoriutumista tukeva teknologia. Eduskunnan kanslian julkaisu, 2001. (In Finnish).

[10] Effective Health Care - Complications of diabetes: Screening for retinopathy and Management of foot ulcers. Volume 5, number 4. Royal Society of Medicine Press, 1999. ISSN 0965-0288.

[11] Rafael C. Gonzalez and Richard E. Woods. Digital Image Processing, 2nd edition.Prentice Hall, 2002. ISBN 0-20118075-8.

[12] John C. Russ. The Image Processing Handbook, 3rd edition, pages 196-197. CRC Press LLC and SpringerVerlag GmbH \& Co. KG, 1999. ISBN 3-540-64747-3.

[13] Suomen Diabetesliitto ry. Diabetes ja silmänpohjamuutokset. Kirjapaino Hermes Oy, 1998. ISBN 951-9406-91-3. (In Finnish).

[14] Suomen Diabetesliiton retinopatiatyöryhmä. Diabeettinen retinopatia: Seuranta,hoito ja näkövammautuneen diabeetikon kuntoutus. Diabetes-lehden lääkäriliite, 1992. (In Finnish).

[15] Sight savers: The structure of the human eye. Website (referenced 9th February 2005). http://www.sightsavers.org.uk/html/eyeconditions/human _eye_detailed.htm.

[16] Wikipedia, the free encyclopedia. Website (referenced 9th February 2005). http://en.wikipedia.org/wiki/Main_Page.

[17] Lars B. Bäcklund. Early Diagnosis of Diabetic Retinopathy by Mass Examinations in Primary Health Care. PhD thesis, Karolinska Institutet, Sweden, 2000. ISBN 91-628-4224-2.

[18] Daniel E. Singer, David M. Nathan, Howard A. Fogel, and Andrew P. Schachat. Screening for diabetic retinopathy. Annals of Internal Medicine, 116:660-671, 1992. 
[19] Retinopathy Working Party. A protocol for screening for diabetic retinopathy in europe. Diabetic Medicine, 8:263-267, 1991.

[20] D. Usher, M. Dumskyj, M. Himaga, T. H. Williamson, S. Nussey, and J. Boyce Automated detection of diabetic retinopathy in digital retinal images: a tool for diabetic retinopathy screening. Diabetes UK. Diabetic Medicine, 21:84-90, 2003.

[21] ThomasWalter, Jean-Claude Klein, Pascale Massin, and Ali Erginay. A contribution of image processing to the diagnosis of diabetic retinopathy - detection of exudates in color fundus images of the human retina. IEEE Transactions on Medical Imaging, 21:1236-1243, October 2002.

[22] Chanjira Sinthanayothin, Viravud Kongbunkiat, Suthee Phoojaruenchanachain, and Apichart Singlavanija. Automated screening system for diabetic retinopathy. In Proceedings of the 3rd International Symposium on Image and Signal Processing and Analysis, pages 915920, 2003.

[23] G. G. Gardner, D. Keating, T.H. Williamson, and A. T. Elliot. Automatic detection of diabetic retinopathy using an articial neural network: a screening tool. British Journal of Ophthalmology, 80:940-944, 1996.

[24] Bernhard M. Ege, Ole K. Hejlesen, Ole V. Larsen, Karina Moller, Barry Jennings,David Kerr, and David A. Cavan. Screening for diabetic retinopathy using computer based image analysis and statistical classification. Computer Methods and Programs in Biomedicine, 62:165-175, 2000.

[25] Huan Wang, Wynne Hsu, Kheng Guan Goh, and Mong Li Lee. An effective approach to detect lesions in color retinal images. In IEEE Conference on Computer Vision and Pattern Recognition (CVPR), pages 181-187, South Carolina, USA, June 2000.

[26] Kheng Guan Goh, Wynne Hsu, Mong Li Lee, and Huan Wang. Adris: an automatic diabetic retinal image screening system. Medical Data Mining and Knowledge Discovery, pages 181-210, 2000.

[27] Huiqi Li and Opas Chutatape. Automated feature extraction in color retinal images by a model based approach. IEEE Transactions on Biomedical Engineering, 51:246-254, February 2004.

[28] Nicholas P. Ward, Stephen Tomlinson, and Christopher J.Taylor. Image analysis of fundus photographs. Ophthalmology, 96:80-86, January 1989.

[29] Russell Phillips, John Forrester, and Peter Sharp. Automated detection and quantification of retinal exudates. Graefe's Archive for Clinical and Experimental Ophthalmology, 231:90-94, 1993.

[30] Wynne Hsu, P. M. D. S. Pallawala, Mong Li Lee, and Kah-Guan Au Eong. The role of domain knowledge in the detection of retinal hard exudates. In IEEE Conference on Computer Vision and Pattern Recognition (CVPR), pages 246-251, Kauai Marriott, Hawaii, December 2001

[31] Alireza Osareh. Automated Identification of Diabetic Retinal Exudates and the Optic Disc. PhD thesis, Department of Computer Sciene, University of Bristol, 2004.
[32] Alireza Osareh, Majid Mirmehdi, Barry Thomas, and Richard Markham. Comparative exudate classification using support vector machines and neural networks. In 5th International Conference on Medical Image Computing and Computer-Assisted Intervention, pages 413-420, Springer LNCS 2489, September 2002.

[33] B. Raman, E. S. Bursell, M. Wilson, G. Zamora, I. Benche, S. C. Nemeth, and P. Soliz. The effects of spatial resolution on an automated diabetic retinopathy screening system's performace in detection microaneurysms for diabetic retinopathy. In Proceedings of the 17th IEEE Symposium on Computer-Based Medical Systems (CBMS'04), pages 128-133, Bethesda, Maryland, 2004.

[34] M. J. Cree, J. A. Olson, K. C. McHardy, J. V. Forrester, and P. F. Sharp. Automated microaneurysm detection. In IEEE International Conference on Image Processing, pages 699-702, Lausanne, Switzerland, 1996.

[35] Mohamed Kamel, Saeid Belkassim, Ana Maria Mendonca, and Aurélio Campilho. A neural network approach for the automatic detection of microaneurysms in retinal angiograms. In International Joint Conference on Neural Networks, pages 2695- 2699, Washington DC, 2001.

[36] Sherif Abdelazeem. Microaneurysm detection using vessel removal and circular hough transform. In Nineteenth National Radio Science Conference, pages 421- 426, Alexandria, Egypt, March 2002.

[37] Mohammed Hafez and Sherif Abdel Azeem. Using adaptive edge technique for detecting microaneurysms in fluorescein angiograms of the ocular fundus. In IEEE Melecon 2002, pages 479-483, Cairo, Egypt, May 2002.

[38] A. M. Mendonca, A. J. Campilho, and J. M. Nunes. Automatic segmentation of microaneurysmsin retinal angiograms of diabetic patients. In 10th International conference on Image analysis and processing, pages 728-733, Venice, Italy, September 1999.

[39] Zheng Liu, Chutatape Opas, and Shankar M. Krishnan. Automatic image analysis of fundus photograph. In Proceedings - 19th International Conference IEEE/EMBS, pages 524-525, Chicago, IL, USA, October 1997.

[40] Gang Luo, Opas Chutatape, Huiqi Li, and Shankar M. Krishnan. Abnormality detection in automated mass screening system of diabetic retinopathy. In Fourteenth IEEE Symposium on Computer-Based Medical Systems, pages 132-137, Bethesda, Maryland, 2001.

[41] Huiqi Li and Opas Chutatape. A model-based approach for automated feature extraction in fundus images. In Ninth IEEE International Conference on Computer Vision Volume 1, pages 394-399, Nice, France, 2003.

[42] Chanjira Sinthanayothin, James F. Boyce, Helen L. Cook, and Thomas H. Williamson. Automated localisation of the optic disc, fovea, and retinal blood vessels from digital colour fundus images. $\mathrm{Br} \quad \mathrm{J}$ Ophthalmol, 83:902-910, 1999.

[43] Alireza Osareh, Majid Mirmehdi, Barry Thomas, and Richard Markham. Automatic recognition of exudative maculopathy using fuzzy C-means clustering and neural networks. In Medical Image Understanding and Analysis, pages 49-52, BMVA Press, July 2001. 
[44] Alireza Osareh, Majid Mirmehdi, Barry Thomas, and Richard Markham. Classification and localisation of diabetic-related eye disease. In 7th European Conference on Computer Vision, pages 502-516, Springer LNCS 2353, May 2002.

[45] Timo Hellstedt, Eija Vesti, and Ilkka Immonen. Identification of individual microaneurysms:a comparison between fluorescein angiograms and red-free and colour photographs. Graefe's Archive for Clinical and Experimental Ophthalmology, 234:13-17, 1996.

[46] Joes Staal, Michael D. Abramoff, Meindert Niemeijer, Max A. Viergever, and Bram van Ginnesen. Ridge-based vessel segmentation in color images of the retina. IEEE Transactions on Medical Imaging, 23:501-509, April 2004

[47] Michael D. Abràmoff, , Mona K. Garvin, Milan Sonka, Fellow Retinal Imaging and Image Analysis Clinical Applications Review ieee reviews in biomedical engineering, VOL. 3, 2010 [48] C. S. Flick, "Centenary of Babbage's ophthalmoscope," Optician, vol.113, p. 246, 1947.

[48] C. R. Keeler, " 150 years since Babbage's ophthalmoscope,” Arch. Ophthalmol.,vol. 115, pp. 14561457, 1997.

[49] D. S. Halacy, Charles Babbage, Father of the Computer. London,U.K.: Crowell-Collier Press, 1970.

[50] H. L. F. von Helmholtz, Beschreibung eines AugenSpiegels. :A.Farstnerische Verlagsbuchhandlung, 1851.

[51] J. E. Purkinje, Beobachtungen und Versuche zur Physiologie der Sinne.Erstes Bandchen, Beitrage zur Kenntniss des Sehens in subjectiver Hinsicht.Prague, Austria: , 1823.
[52] O. Gerloff, "Uber die Photographie des Augenhintergrundes," KlinMonatsblätter Augenheilkunde, vol. 29, pp. 397-403, 1891

[53] A. Gullstrand, "Neue methoden der reflexlosen ophthalmoskopie Berichte Deutsche Ophthalmologische Gesellschaft, vol. 36, 1910.

[54] H. R. Novotny and D. L. Alvis, "A method of photographing fluorescence in circulating blood in the human retina," Circulation, vol. 24,pp. 82-86, 1961.

[55] L. Allen, "Ocular fundus photography: Suggestions for achieving consistently good pictures and instructions for stereoscopic photography,"Amer. J. Ophthalmol., vol. 57, pp. 13-28, 1964.

[56] R. H. Webb and G. W. Hughes, "Scanning laser ophthalmoscope," IEEE Trans. Biomed. Eng., vol. 28, no. 4, pp. 488-492, Apr. 1981.

[57] D. Huang, E. A. Swanson, C. P. Lin, J. S. Schuman, W. G. Stinson, W. Chang, M. R. Hee, T. Flotte, K. Gregory, C. A. Puliafito, and J.G. Fujimoto, "Optical coherence tomography," Science, vol. 254, no. 5035, pp. 1178 1181, Nov. 1991

[58] M. E. J. van Velthoven, D. J. Faber, F. D. Verbraak, T G. van Leeuwen, and M. D. de Smet, "Recent developments in optical coherence tomography for imaging the retina," Prog. Retina Eye Res., vol. 26, no. 1, pp.57-77, Jan. 2007.

[59] M. Matsui, T. Tashiro, K. Matsumoto, and S. Yamamoto, "A study on automatic and quantitative diagnosis of fundus photographs. I. Detection of contour line of retinal blood vessel images on color fundus photographs (author's transl.)," Nippon Ganka Gakkai Zasshi, vol. 77, no8 8, pp. 907-918, 1973, [Online]. Available: PM:4594062 